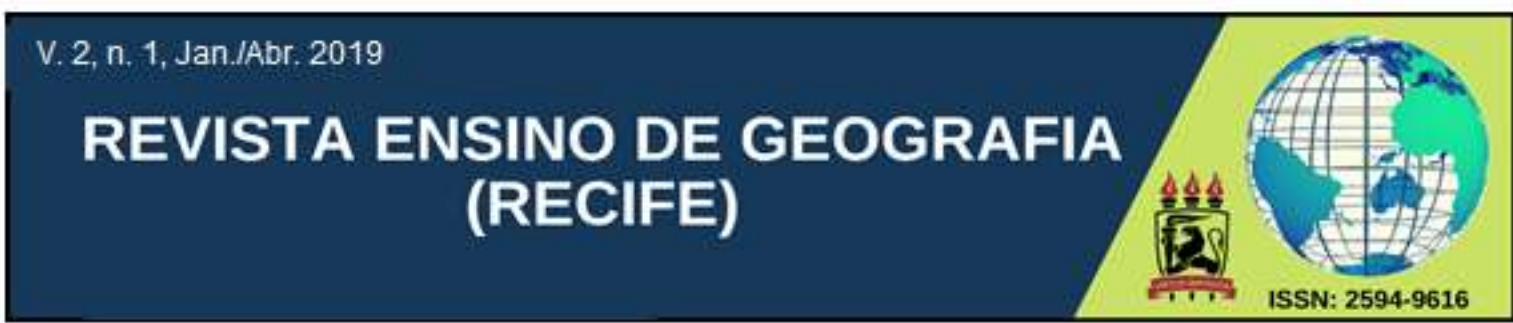

\title{
USO DO TEATRO DE FANTOCHES SOBRE AS REGIÕES BRASILEIRAS NAS AULAS DE GEOGRAFIA DO ENSINO FUNDAMENTAL: UMA EXPERIÊNCIA DO PIBID/GEOGRAFIA/UFSM 2018
}

\author{
Natália Lampert Batista \\ Doutoranda em Geografia, Docente da Educação Básica e supervisora \\ PIBID/Geografia/UFSM 2018/2019 \\ natilbatista3@gmail.com \\ ORCID iD: https://orcid.org/0000-0002-1884-2340 \\ Renata Carvalho Arruda \\ Graduanda em Geografia Licenciatura (UFSM) \\ ree.carvalho7@gmail.com \\ ORCID iD: https://orcid.org/0000-0002-8377-2748 \\ Michel Vidal Simões \\ Graduando em Geografia Licenciatura (UFSM) \\ michelvidal608@gmail.com \\ ORCID iD: https://orcid.org/0000-0002-1884-2340 \\ Larissa Bassan \\ Graduanda em Geografia Licenciatura (UFSM) \\ larissa_b1998@gmail.com \\ ORCID iD: https://orcid.org/0000-0002-6460-7878 \\ Maurício Pase Leite \\ Graduando em Geografia Licenciatura (UFSM) \\ mauricio.leite@gmail.com \\ ORCID iD: https://orcid.org/0000-0002-1884-2340
}

Artigo recebido em 27/12/2018 e aceito em 30/04/2019

\begin{abstract}
RESUMO: A temática regionalização brasileira integra o currículo do $7^{\circ}$ ano do Ensino Fundamental da EMEF Junto ao CAIC Luizinho de Grandi, devendo, assim, ser abordada com os estudantes de forma lúdica e interativa para desenvolver noções críticas e reflexivas sobre a organização do espaço do nosso país. Assim, pensou-se a presente proposta pedagógica pautada no Teatro de Fantoches como ferramenta mediadora da construção de saberes. Teve-se como objetivo da atividade fazer com que os estudantes de Educação Básica desenvolvam habilidades e competências para reconhecer as disparidades e semelhanças entre as Regiões Brasileiras (classificação do IBGE), comparando e compreendendo o porquê dessa regionalização. Além disso, pretendeu-se identificar os "tipos culturais" de cada região do Brasil, desmistificar os estereótipos comumente associados a cada parte do país e produzir um Teatro de Fantoches sobre a temática regionalização, estimulando
\end{abstract}


a criatividade e a produção textual entre os alunos. Toda a proposta pedagógica contou com o acompanhamento e monitoria dos bolsistas PIBID/Geografia/UFSM, nos meses de Setembro e Outubro de 2018. Com base nas atividades desenvolvidas, concluímos que a proposta pedagógica ajudou a consolidar muitos conhecimentos acerca da temática regionalização brasileira entre os estudantes da Educação Básica e foi uma experiência enriquecedora aos bolsistas PIBID/Geografia/UFSM por vivenciarem a sala de aula e interagirem com o seu futuro campo de atuação. Portanto, acreditasse que a proposta logrou êxito e cumpriu o seu papel enquanto uma intervenção pedagógica que colabora com a aprendizagem dos estudantes da Educação Básica e, de mesmo modo, com a formação dos futuros docentes de Geografia.

PALAVRAS-CHAVE: Ensino de Geografia. Teatro de Fantoches. Monitorias do PIBID Geografia.

\title{
THE USE OF THE PUPPET THEATER ON THE BRAZILIAN REGIONS IN THE GEOGRAPHY DAYS OF FUNDAMENTAL TEACHING: AN EXPERIENCE OF PIBID/GEOGRAPHY/UFSM 2018
}

\begin{abstract}
The Brazilian regionalization theme integrates the 7th grade curriculum of the EMEF Junto ao CAIC Luizinho de Grandi, so it should be approached with the students in a playful and interactive way to develop critical and reflexive notions about the organization of the space of our country. Thus, the present pedagogical proposal ruled in the Theater of Puppets as mediating tool of the construction of knowledge. The purpose of the activity was to make the students of Basic Education develop skills and competences to recognize the disparities and similarities between the Brazilian Regions (IBGE classification), comparing and understanding the reason for this regionalization. In addition, it was intended to identify the "cultural types" of each region of Brazil, to demystify the stereotypes commonly associated with each part of the country and to produce a Puppet Theater on the theme of regionalization, stimulating creativity and textual production among students. The entire pedagogical proposal was monitored by PIBID/Geography/UFSM scholarship holders in September and October 2018. Based on the activities carried out, we concluded that the pedagogical proposal helped to consolidate many knowledge about the Brazilian regionalization theme among the students of Basic Education and it was an enriching experience to the scholars PIBID/Geography /UFSM for experiencing the classroom and interacting with its future field of activity. Therefore, believe that the proposal was successful and fulfilled its role as a pedagogical intervention that collaborates with the learning of students of Basic Education and, similarly, with the training of future teachers of Geography.
\end{abstract}

Keywords: Geography Teaching. Puppet Theater. Monitoring of PIBID Geography.

\section{INTRODUÇÃO}

O Programa Institucional de Iniciação à Docência (PIBID) tem como objetivo “incentivar a formação de docentes para a Educação Básica a nível superior, elevar a qualidade da formação inicial de professores nos cursos de licenciatura, promovendo a integração entre educação superior e educação básica e a melhoria de qualidade da educação pública brasileira" (BRASIL, s/d). Assim sendo, a partir do Programa, os graduandos de licenciaturas desenvolvem atividades pedagógicas em Escolas da rede pública conveniadas ao PIBID, sob a supervisão de um professor da Educação Básica e de um Coordenador Institucional de Área da Educação Superior. O Programa contribui para a articulação entre teoria e prática necessárias à formação dos futuros docentes e promove uma co-formação (inicial e continuada) de professores.

Na Universidade Federal de Santa Maria (UFSM), o PIBID Geografia desenvolve suas atividades em três escolas-campo, dentre elas a EMEF Junto ao CAIC Luizinho de Grandi 
(Figura 1), localizada na região administrativa Sul de Santa Maria/RS. Na referida Escola há duas modalidades de inserção dos bolsistas: uma se refere às oficinas pedagógicas propostas pelos bolsistas de graduação e realizadas em turno inverso as aulas dos estudantes e a outra se refere ao acompanhamento pelos graduandos das atividades desenvolvidas pela Professora Supervisora em sala de aula. O presente relato se vincula à segunda modalidade. Assim, os bolsistas auxiliaram no desenvolvimento da proposta pedagógica ofertada pela Professora Supervisora em três turmas de $7^{\circ}$ ano do Esnino Fundamental (aproximadamente 75 alunos) sobre temática Divisão Regional Brasileira.

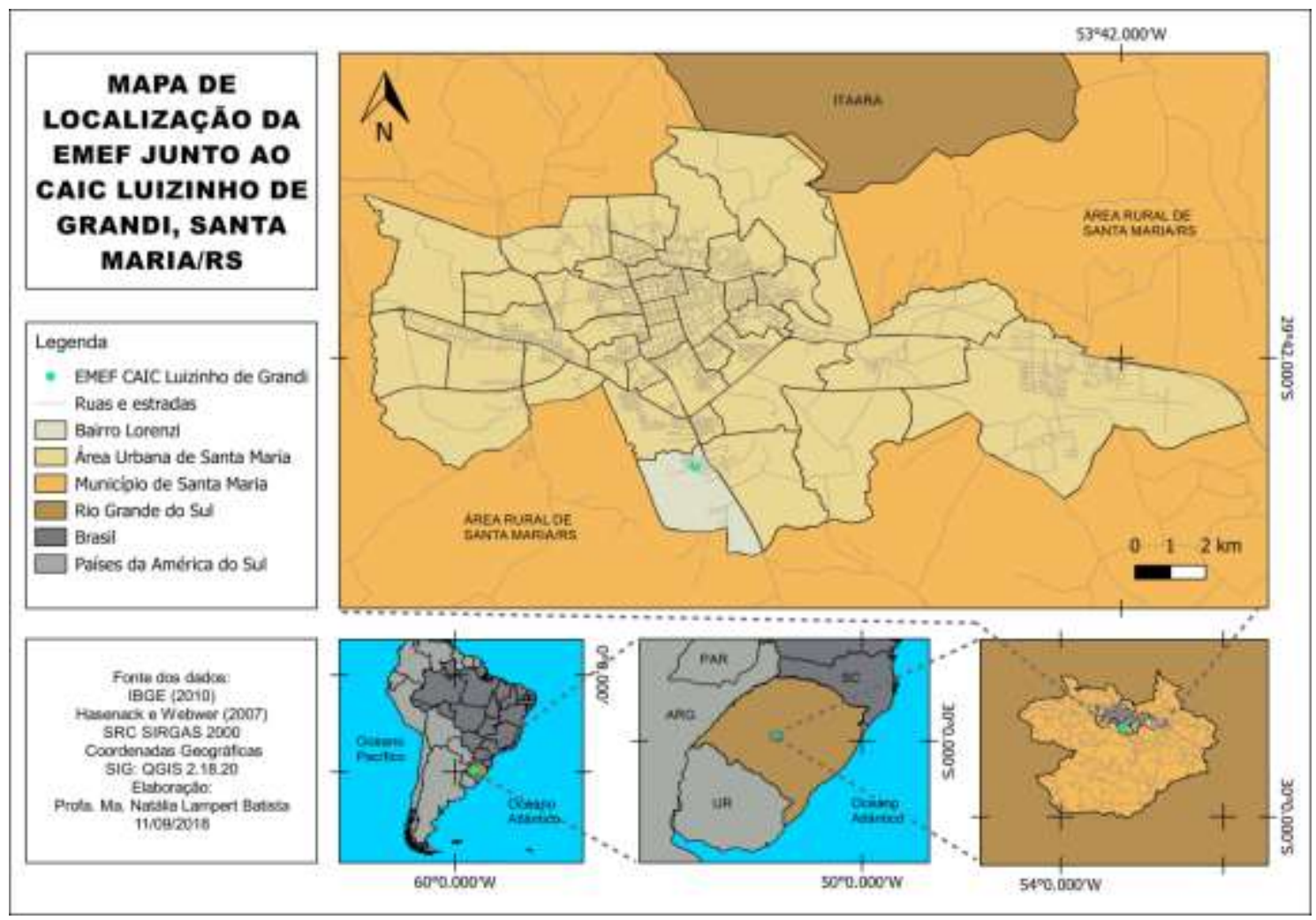

Figura 1: Mapa de localização da Escola Municipal de Ensino Fundamental Junto ao CAIC Luizinho de Grandi.

Para a realização proposta pedagógica, os bolsistas PIBID/Geografia/UFSM primeiramente observaram duas aulas em cada turma e conheceram brevemente o contexto dos estudantes, bem como se interaram da atividade que já estava sendo realizada com os alunos do Esnino Fundamental. Após, acompanharam e auxiliaram o desenvolvimento do Plano de Aula, intervindo e colaborando com a prática docente em sala de aula, com a aprendizagem dos alunos de Educação Básica e com a sua formação enquanto futuros professores de Geografia. 
Quanto a temática trabalhada, ressalta-se que segundo Auzani et al (2014), a cultura brasileira incorporou as especificidades dos povos que se inseriram no espaço geográfico brasileiro ao longo do seu processo histórico de formação. "Assim, as regiões do Brasil apresentam traços culturais provenientes dos diferentes agentes sociais que povoaram o País" (p. 82) e precisam ser estudadas e debatidas com os estudantes de Educação Básica. A proposta de estudar as regiões por meio do Teatro de Fantoches é "a de uma construção coletiva que privilegie a interação e a utilização de diferentes linguagens" (SOUZA, 2013, p. 67) no ensino de Geografia.

Dessa forma:

\begin{abstract}
O estudo das regiões brasileiras faz parte da grade curricular do $7^{\circ}$ ano do Ensino Fundamental e permite que os educandos conheçam o espaço geográfico, desde o processo de colonização até os dias atuais, bem como as mudanças ocorridas ao longo dos anos. Ensinar Geografia na contemporaneidade requer práticas diferenciadas e que contribuam para uma aprendizagem significativa. Pensando nisto, é necessário fazer com que os alunos compreendam o território brasileiro, refletindo sobre as potencialidades e as fragilidades deste recorte espacial (AUZANI et al, 2014, p. 81).
\end{abstract}

Neste sentido, o Teatro de Fantoche se torna uma alternativa viável e enriquecedora para as aulas de Geografia, potencializando o processo de ensino e de aprendizagem das temáticas geográficas, como a regionalização brasileira, e diversifica as formas de abordagem do tema, o que motiva e engaja os estudantes. Assim, a proposta torna-se relevante e coerente com a dinamização das aulas de Geografia na Educação Básica.

Há várias formas de regionalizar o país. As mais debatidas em sala de aula se referem à regionalização do Instituto Brasileiro de Geografia e Estatística (IBGE) e as Regiões Geoeconômicas (ou Complexos Regionais), propostas pelo geógrafo brasileiro Pedro Pinchas Geiger. Na EMEF Junto ao CAIC Luizinho de Grandi, optou-se por trabalhar com os alunos as Regiões do IBGE (Figura 2) devido a maior disponibilidade e facilidade de encontrar de dados oficiais para a realização de mapeamentos sobre temas vinculados as regiões como características populacionais, renda, migrações, entre outros. Além disso, o livro didático adotado na Escola (ADAS; ADAS, 2015) aborda o conteúdo sob o enfoque dessa regionalização e, apesar deste não ser o único recurso utilizado em sala de aula, é uma fonte de consulta importante aos alunos dessa comunidade periférica de Santa Maria/RS. 


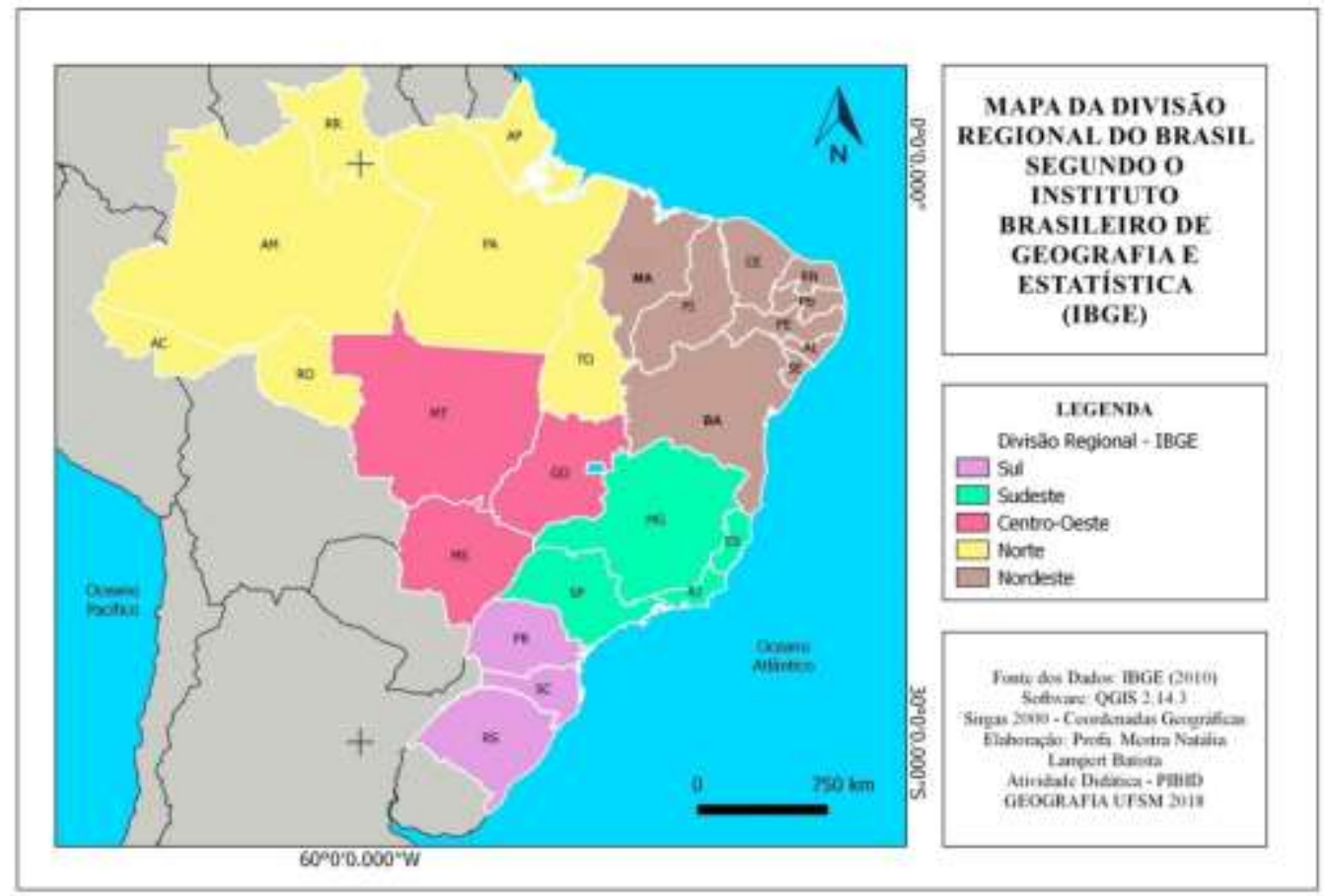

Figura 2: Mapa da divisão regional do Brasil segundo o IBGE.

Com base nas premissas apresentadas, a proposta pedagógica teve como objetivo fazer com que os estudantes de Educação Básica desenvolvam habilidades e competências que auxiliem no reconhecimento das disparidades e das semelhanças entre as Regiões Brasileiras (classificação do IBGE), comparando e compreendendo o porquê dessa regionalização. Além disso, pretendeu-se identificar os "tipos culturais" de cada região do Brasil, desmistificar os estereótipos comumente associados a cada parte do país e produzir um Teatro de Fantoches sobre a temática regionalização, estimulando a criatividade e a produção textual entre os alunos. Na sequência, foi relatada a proposta desenvolvida na EMEF Junto ao CAIC Luizinho de Grandi, assim como se apresentou os relatos de vivência dos bolsistas PIBID/Geografia/UFSM envolvidos na atividade relatada (Figura 3).

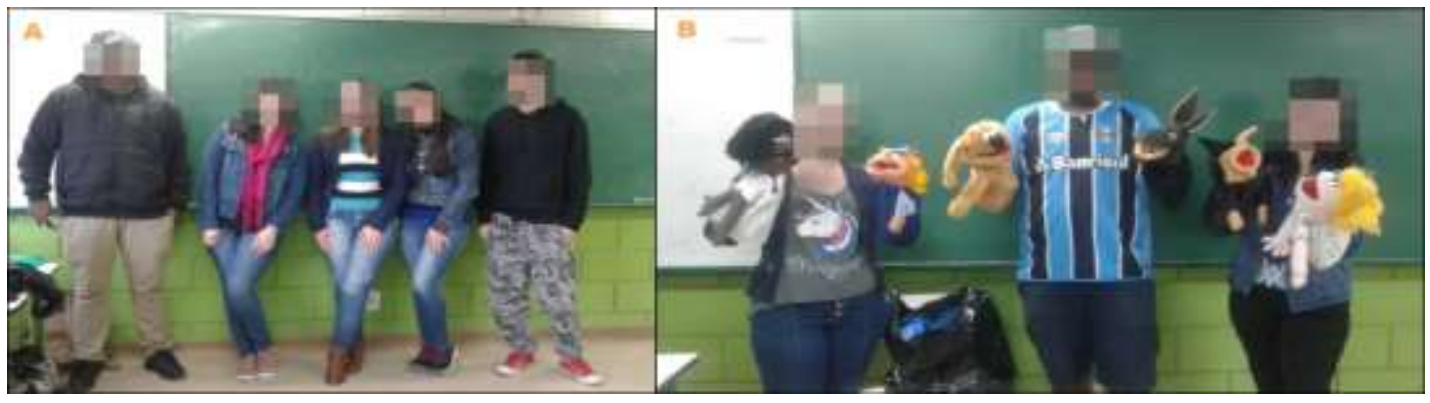

Figura 3: A e B) Bolsistas PIBID Geografia UFSM envolvidos na proposta didática. Fonte: Atividade Didática, 2018. 


\title{
2 "BRASIL REGIONAL: QUEM VIVE EM CADA REGIÃO DO PAÍS?": TEATRO DE FANTOCHES E ENSINO DE GEOGRAFIA
}

O lúdico, a interatividade e o protagonismo discente e docente no ensino de Geografia podem colaborar significativamente com o desenvolvimento de conhecimentos geográficos capazes de estimular o pensamento crítico-reflexivo e cidadão dos alunos, por meio da construção das noções de identidade e de pertencimento. Segundo Castellar e Moraes (2010, p.15):

\begin{abstract}
A educação geográfica contribui para a formação do conceito de identidade, expresso de diferentes formas: na consciência de que somos sujeitos da história; nas relações com lugares vividos; nos costumes que resgatam nossa memória social; na identificação e comparação de valores e períodos que explicam a nossa identidade cultural; na compreensão perceptiva da paisagem que ganha significados, à medida que, ao observá-la, nota-se a vivência dos indivíduos.
\end{abstract}

Assim, a proposta pedagógica aqui descrita tem como foco estimular nos alunos o desejo de conhecer e de aprender sobre o país onde vivem de forma mais interativa e lúdica, ou seja, mediada pelo Teatro de Fantoches. Neste sentido, os personagens criados pelos próprios alunos da Educação Básica por meio das pesquisas realizadas pelos estudantes, suas falas e os cenários confeccionados retrataram o contexto espacial e temporal de cada região brasileira e "evidenciam o desejo e a busca incessante pelo conhecimento pela arte" (BATISTA; ROUBUSTE; BECKER, 2014, p. 40).

Como tal, ao destacar o uso de fantoches no ensino de Geografia, Brandão e Melo (2013, p. 91) mencionam que "[...] o fantoche pode ser um elemento que possibilita avanços no processo cognitivo, especialmente quando [...] com a confecção e manipulação dos fantoches, é possível explorar o conceito de espaço, lugar e orientação, a fim de descentralizar do aluno de sua visão egocêntrica".

Já Souza (2013, p. 66) acrescenta que:

A Geografia deve incentivar o aluno a ler o mundo com olhar observador, desafiado e desafiador, buscando uma leitura plural da realidade para que se amplie o horizonte de conhecimento e análise do observador-leitor. Nesta perspectiva, o teatro surge como um aliado na busca por olhares diferentes sobre a realidade. Propõe uma abertura para a espontaneidade; a criatividade e o trabalho coletivo. Um ensino, no qual os alunos atuem como agentes de seu conhecimento, com autonomia e liberdade, e os professores mediem, coordenem e direcionem as ações a serem realizadas. 
Como forma de efetivação da prática das atividades, inicialmente a Professora Supervisora trabalhou teoricamente a temática regionalização brasileira com as turmas de $7^{\circ}$ ano, bem como realizou atividades práticas de mapeamento digital e de caracterização de sobre cada Região do IBGE junto aos estudantes. Após isso, com a inserção dos bolsistas PIBID/Geografia/UFSM na Escola, os mesmos assistiram duas aulas (de cada turma) para se inteirarem sobre a prática em andamento. Essa primeira inserção é destacada no relato a seguir:

\begin{abstract}
A sensação de entusiasmo, curiosidade e desafios permearam a primeira visita a escola CAIC, um ambiente com diversas nuance de cores que nos instigaram ao mesmo tempo em que intimidaram, pois qual o estudante de licenciatura que não sentiria este misto de sentimentos? A Escola é um ambiente que nos trouxe conforto, pois não há melhor espaço para um futuro professor do que as salas de aulas, os corredores, o pátio e toda aquela atmosfera que este espaço de ensino propicia, nas poucas horas que estivemos na companhia destes estudantes (curiosos e habilmente empenhados em chamar nossa atenção, afinal os tiramos de suas rotinas e invadimos literalmente o seu espaço). Foi possível minimamente entender e compreender os desafios que permeiam a rotina de um professor, tendo a absoluta certeza que muitos serão os nossos também, mas com a vontade renovada e a certeza de ter escolhido o caminho certo a seguir com a consciência de que é apenas o início da nossa jornada e que ela possa ser de construção coletiva de muitos aprendizados e reflexões. (Bolsista PIBID/Geografia/UFSM - Renata Carvalho Arruda, Setembro de 2018).
\end{abstract}

A observação de prática em sala de aula contribuiu com a reflexão sobre a atuação e o papel do professor de Geografia em sala de aula, bem como para aproximar os bolsistas PIBID/Geografia/UFSM dos estudantes de Educação Básica, promovendo o intercâmbio de saberes entre ambos. Após essa observação, os bolsistas passaram a intervir na prática para a realização do Teatro de Fantoches, produzido para síntese e fixação dos conhecimentos abordados com os alunos ao longo do ano de 2018.

Como sequência da abordagem dos conteúdos, dividiu-se os estudantes da Educação Básica em 5 grupos (etapas realizadas para cada turma), cada grupo sorteou uma região para desenvolver a sua abordagem e realizou pesquisas no material de aula, no Livro Didático, em sites no Laboratório de Informática e em casa sobre o tema que lhes coube. Após, sistematizaram um quadro síntese de cada região do Brasil, segundo o IBGE, contendo informações socioeconômicas, naturais/ambientais, turísticas, curiosidades, entre outras (Figura 3A). De posse desses dados, produziram um roteiro para o Teatro de Fantoches (Figura 3B). Para isso, criaram personagens, um contexto e um texto para ser apresentado aos colegas. Após, produzir os textos bases, produziram os cenários (Figura 3C) e escolheram os Fantoches a serem utilizados em suas apresentações. Esse processo de construções teve a duração de cinco períodos de 50 minutos. 


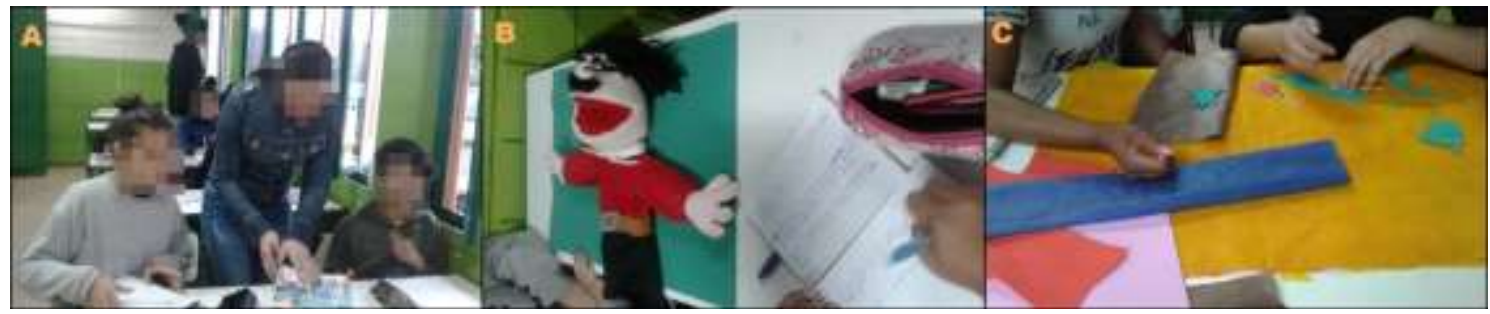

Figura 3: A) Pesquisas sobre as Regiões Brasileiras; B) Organização dos roteiros do Teatro de Fantoches;

C) Confecção dos Cenários para o Teatro de Fantoches. Fonte: Atividade Didática, 2018.

\title{
Durante esse processo de construção, os bolsistas PIBID/Geografia/UFSM auxiliaram
}

os grupos na produção dos seus materiais e interagiram com os estudantes na mediação da construção dos conhecimentos geográficos. Essa interação foi produtiva para ambos, pois permitiu aos estudantes de Educação Básica uma atenção mais individualizada com a monitoria dos bolsistas e aos graduandos o exercício inicial da docência. A sequência da atividade pode ser observada no relato subsequente:

\begin{abstract}
Nessa inserção em sala de aula, na escola CAIC, foi clara a maior interação dos alunos com os pibidianos, isso porque na primeira inserção os alunos não estavam habituados com aulas com a presença de mais pessoas em sala de aula. [...] É imprescindível destacar também que na segunda inserção em sala de aula, foi perceptível a questão da maior autonomia para com os alunos e com o conteúdo trabalhado. O Pibid está proporcionando aos pibidianos a criação de uma melhor formação acadêmica e também futuramente profissional, pois é nesse momento que a partir das observações que fizemos podemos nos corrigir, para que assim nos tornemos excelentes professores. Assim sendo, a segunda inserção em sala de aula foi boa e produtiva e a conclusão que se obtém é que para os pibidianos foi uma aula ainda mais autônoma, na qual podemos ter maior flexibilidade com o conteúdo e também com a desenvoltura em sala de aula para falar e se expressar. Além disso, pode-se dizer que essas inserções em sala de aula enriquece não apenas a nossa formação como futuros professores, mas também a formação dos alunos da escola CAIC, pois o Pibid está começando a proporcionar isso e de certa forma é muito importante a obtenção de conhecimento e de experiência. (Bolsista PIBID/Geografia/UFSM - Larissa Bassan, setembro de 2018).
\end{abstract}

A sequência de inserções dos bolsistas PIBID/Geografia/UFSM, todavia,

evidenciaram interfaces da realidade escolar, muitas vezes, distantes das teorias abordadas nas aulas da graduação e que remontam os desafios da docência. Conforme a explanação abaixo:

Esta segunda-feira chuvosa nos mostrou uma realidade um tanto quanto curiosa, devido às condições climáticas tínhamos pouquíssimos alunos. Com isso, nosso plano de aula que era trabalhar com na produção dos fantoches dos personagens de cada região do Brasil ficou inviável. No entanto, a professora Natália tinha um plano $\mathrm{B}$, que era trabalharmos na produção de um cartaz para expormos os trabalhos realizados pelos alunos com as intervenções de nós pibidianos. Nosso trabalho foi muito produtivo, apesar de ser diferente do que imaginamos, os alunos trabalharam de forma cooperativa na produção do material. Outro aspecto positivo foi à interação que tivemos com os alunos nos permitindo conhecê-los melhor, saber de suas 
realidades e perspectivas. (Bolsista PIBID/Geografia/UFSM - Maurício Pase Leite, Outubro de 2018).

Essa observação possibilitou evidenciar a questão da flexibilidade do Planejamento, bem como da necessidade de o Professor estar preparado para as diversas situações que surgem no cotidiano escolar. Todavia, na aula seguinte as produções dos estudantes foram finalizadas e organizaram-se as apresentações dos Teatros de Fantoches (Figura 4A). Na semana posterior, em dois períodos de 50 minutos, os estudantes apresentaram as Peças e debateram os conteúdos abordados com os demais colegas e com os bolsistas PIBID/Geografia/UFSM.

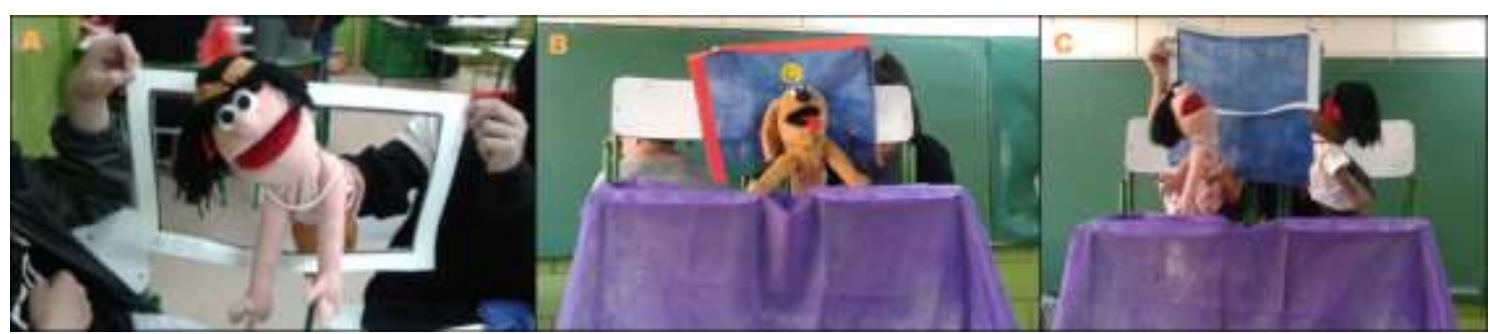

Figura 4: A) Organização das apresentações dos Teatros de Fantoches; B e C) Apresentações dos Teatros de Fantoches. Fonte: Atividade Didática, 2018.

O relato a seguir, destaca essa última etapa do Plano de Aula, retratando a finalização da produção dos Cenários, escolha dos Fantoches e apresentações:

\begin{abstract}
No nosso último encontro na escola CAIC, tínhamos bastante alunos em sala de aula, desta forma foi possível começar de vez a elaboração dos personagens que foram escolhidos em sala de aula para a identificação de cada região pelos alunos. Desta forma foi realizado a montagens dos cenários, para que eles possam fazer a apresentação das regiões e seus personagens. No dia de hoje foi visto em sala de aula que os alunos têm a criatividade bem objetiva para a identificação e criação dos cenários, alguns com mais facilidade do que outros, mais de certa a forma a aula foi bem produtiva. Os bonecos foram os protagonistas principais na hora da escolha, pois os alunos ao verem os bonecos já começaram a ver qual boneco seria o melhor protagonista, para os personagens escolhidos por suas regiões. E neste dia de hoje, foi o dia que os alunos começaram a colar os cartazes, com as características das regiões que cada grupo havia sido sorteado para fazer a descrição na parede da sala de aula e apresentaram suas peças teatrais. (Bolsista PIBID/Geografia/UFSM Michel Vidal Simões, Outubro de 2018).
\end{abstract}

As peças teatrais foram bem diversificadas. Assim como alguns grupos escolheram "personagens típicos" de cada região, outros escolheram personagens exóticos ao estereótipo regional e, desse modo, destacaram as questões vinculadas às migrações, que também haviam sido estudadas, por exemplo, um grupo escolheu um Fantoche trajado de gaúcho para viver na Região Norte, expondo assim a Expansão da Fronteira Agrícola, a inserção dos gaúchos na 
Região Norte (Amazônia brasileira) e desmistificando o olhar sobre "quem vive" em cada região.

Portanto, a prática desenvolveu habilidades e competências que possibilitaram os alunos da Educação Básica reconhecerem as disparidades e semelhanças entre as Regiões Brasileiras, segundo a classificação do IBGE, e facilitando seus entendimentos sobre o porquê dessa regionalização. Toda a proposta contribuiu com a construção de conhecimentos sobre o país em que vivemos e sobre a grande diversidade cultural, social, natural, economia e ambiental existente no nosso país.

\section{CONCLUSÃO}

Com base nas atividades realizadas durante o acompanhamento/monitoria dos bolsistas PIBID/Geografia/UFSM às aulas de Geografia, de Setembro e Outubro, na EMEF Junto ao CAIC Luizinho de Grandi, concluímos que a Proposta Pedagógica motivou os estudantes a relembrarem conhecimentos trabalhados nas aulas de Geografia ao longo do ano de 2018, bem como ampliou e consolidou muitos conhecimentos acerca da temática regionalização brasileira. Por outro lado, foi uma experiência enriquecedora aos bolsistas PIBID/Geografia/UFSM, especialmente, por ser a primeira inserção no espaço escolar para alguns deles. Essa introdução às vivências escolares como futuros docentes foi carregada de expectativas e de motivações para a construção de uma prática que estimulasse os estudantes a se interessarem pelos conhecimentos geográficos e que retomasse os saberes de modo prático e interativo. Portanto, acreditasse que a proposta atingiu os objetivos a que se propôs possibilitando uma intervenção pedagógica que colabora com o ensino e com a aprendizagem dos estudantes da Educação Básica e, de mesmo modo, com a formação dos futuros docentes de Geografia.

\section{REFERÊNCIAS}

ADAS, M. ADAS, S. Expedições Geográficas: $7^{\circ}$ ano. 2. ed. São Paulo: Moderna, 2015.

AUZANI,G. M; SCALAMATO, A. T; SEQUEIRA, A. O; LORENSI, D. C. T; REIS, R. M. Objetos Lúdicos: Retratando as Regiões Brasileiras. In: Thaumazein (Santa Maria), v. 7, p. 80-93, 2014. Disponível em: https://www.periodicos.unifra.br/index.php/thaumazein/index. Acessado em 26 de dezembro de 2018.

BATISTA, N. L; ROUBUSTE, L. S; BECKER, E. L. S. Educando para valorização do patrimônio na perspectiva do belo e da estética: o caso do Theatro Treze de Maio, Santa 
Maria, Rio Grande do Sul, Brasil. In: Geosaberes: Revista de Estudos Geoeducacionais, v. 5, p. 36, 2014. Disponível em: http://www.geosaberes.ufc.br/geosaberes/article/view/267. Acessado em 26 de dezembro de 2018.

BRANDÃO, I. D. N; MELLO, M. C. O. Recursos didáticos no ensino de Geografia: tematizações e possibilidades de uso nas práticas pedagógicas. In: Geografia e Pesquisa (UNESP. Ourinhos), v. 7, p. 81-97, 2013. Disponível em: http://vampira.ourinhos.unesp.br/openjournalsystem/index.php/geografiaepesquisa/index. Acessado em 26 de dezembro de 2018.

BRASIL. Sobre o Programa Institucional de Iniciação a Docência. s/d. Disponível em: http://www.capes.gov.br/educacao-basica/capespibid/pibid. Acessado em 11 de dezembro de 2018.

CASTELlaR, S. M. V; MORAES, J. V. Ensino de Geografia. São Paulo: Thompson, 2010.

SOARES, L. M. S. Teatralizando o ensino de Geografia. In: Revista Brasileira de Educação em Geografia, v. 3, p. 57-81, 2013. Disponível em:

http://www.revistaedugeo.com.br/ojs/index.php/revistaedugeo. Acessado em 26 de dezembro de 2018. 